\title{
Evaluation of capillary blood glucose versus a high- risk questionnaire for screening for undiagnosed diabetes mellitus in Eastern province, Saudi Arabia
}

N.A. Al-Baghli, ${ }^{1}$ K.A. Al-Turki, ${ }^{1}$ A.J. Al-Ghamdi, ${ }^{2}$ K. Prasad, ${ }^{3}$ A.Z. Taha ${ }^{4}$ and S.M. Al-Almaie ${ }^{4}$

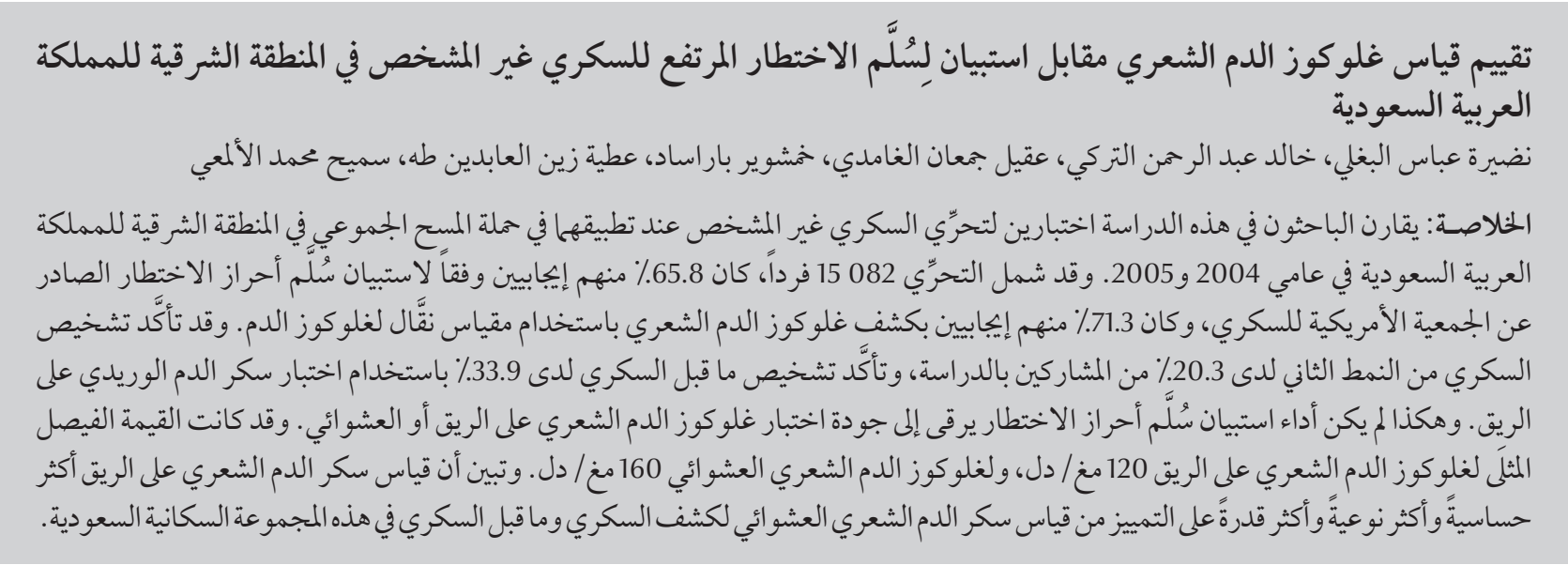

ABSTRACT This study compared 2 screening tests for detecting undiagnosed diabetes mellitus when applied in a mass-screening campaign in the Eastern province of Saudi Arabia in 2004-05. Of 15082 individuals screened, $65.8 \%$ were positive by the American Diabetes Association risk-score questionnaire and $71.3 \%$ by determination of capillary blood glucose (CBG) using a portable glucometer. Type 2 diabetes mellitus was confirmed in $20.3 \%$ of participants and pre-diabetes in 33.9\% using fasting venous blood testing. The risk-score questionnaire did not perform well versus fasting and random CBG. Optimal cut-offs for fasting and random CBG were $120 \mathrm{mg} / \mathrm{dL}$ and $160 \mathrm{mg} / \mathrm{dL}$ respectively. Fasting CBG had higher sensitivity, specificity and discriminating ability than random CBG for detection of diabetes and pre-diabetes in this population.

Évaluation de la mesure de la glycémie capillaire comparée à l'administration d'un questionnaire de dépistage destiné aux personnes à haut risque de diabète jamais diagnostiqué auparavant dans la province orientale d'Arabie saoudite

RÉSUMÉ La présente étude a comparé deux méthodes de dépistage du diabète non diagnostiqué, utilisées pendant une campagne de dépistage de masse dans la province orientale d'Arabie saoudite entre 2004 et 2005. Parmi les 15082 personnes dépistées, le diagnostic de diabète a été posé au moyen du questionnaire de risque de I'American Diabetes Association pour 65,8 \%, et il a été effectué par détermination de la glycémie capillaire à l'aide d'un lecteur de glycémie portable pour 71,3\%. Le diabète de type 2 a été confirmé dans 20,3\% des cas et un état prédiabétique a été diagnostiqué chez 33,9 \% des personnes dépistées au moyen d'une analyse de la glycémie à jeun par prélèvement veineux. Le questionnaire de risque était moins performant que l'analyse de la glycémie à jeun et l'analyse de la glycémie capillaire aléatoire. La valeur seuil optimale pour l'analyse de la glycémie à jeun était $120 \mathrm{mg} / \mathrm{dl}$ et celle de l'analyse capillaire aléatoire était $160 \mathrm{mg} / \mathrm{dl}$. L'analyse de la glycémie à jeun avait une sensibilité plus élevée, une spécificité supérieure et une meilleure capacité de discrimination que l'analyse de la glycémie capillaire aléatoire pour le dépistage du diabète et des états prédiabétiques dans cette population.

'Directorate of Health Affairs, Ministry of Health, Dammam, Saudi Arabia (Correspondence to N.A.Al-Baghli: nadiraa@windowslive.com). ${ }^{2}$ Ministry of Health, Riyadh, Saudi Arabia.

${ }^{3}$ Department of Medical Education, Collage of Medicine, Arabian Gulf University, Bahrain.

${ }^{4}$ Department of Family and Community Medicine, Collage of Medicine, University of Dammam, Dammam, Saudi Arabia.

Received: 28/12/08; accepted: 01/03/09 


\section{Introduction}

The debate whether to screen for diabetes mellitus (DM) continues in the medical community among those who recommend [1] and those who discourage it [2]. Although it seems intuitive that early detection improves outcome, lack of direct evidence from randomized controlled studies of the effectiveness of screening for type $2 \mathrm{DM}$ is the main barrier to its widescale application. Nonetheless, type 2 diabetes may remain undetected for several years [3], and by the time of clinical diagnosis many people have developed one or more micro- or macrovascular diabetic complications [4].

The American Diabetes Association (ADA) has recommended regular screening for type 2 diabetes at 3-year intervals, beginning at age 45 years (or less if there are other risk factors) [1]. However, mass screening was not recommended. To save community resources, the ADA suggested using a screening questionnaire - "take the test, know the score" - whereby only those with high risk-factor scores would be tested [5]. While different diabetes risk questionnaires have been developed and evaluated [6-10], their validity has been mainly assessed in Caucasian populations, which raises doubts over their validity in other populations. When diabetes risk scores have been applied to other ethnic groups, e.g. in Caribbean and South Asian people living in the United Kingdom (UK) [11], the results vary, and the need to validate screening tests in other populations has been emphasized.

The prevalence of DM is very high in the Saudi Arabian population [12], but the performance of screening tests has not yet been validated in this population. Capillary blood glucose (CBG) screening for type $2 \mathrm{DM}$, using a reflectance blood glucose meter, is less costly than other screening tests.

The aim of the present study was to compare 2 screening tests for detecting undiagnosed diabetes when applied in a Saudipopulation through a mass screening campaign in the Eastern province of Saudi Arabia. The study compared the performance of a diabetes risk-score questionnaire in a Saudi population with CBG testing by portable glucometer and determined which cut-offlevels of random and fasting $\mathrm{CBG}$ yielded the best balance between sensitivity and specificity versus laboratory-confirmed fasting plasma glucose (FPG) testing.

\section{Methods}

\section{Sample}

This study was part of a larger screening campaign conducted in the Eastern province of Saudi Arabia between 28 August 2004 and 18 February 2005. The campaign and sampling has been described previously $[13,14]$. The target population was all Saudi residents of the Eastern province, aged 30 years and above, excluding pregnant women (650 000 subjects). They were invited to participate in a screening campaign for the early detection of DM and hypertension by attending one of the $300+$ examination centres in the programme. A total of 15082 individuals were included in the study reported here.

Individuals with undiagnosed diabetes who did screening of either fasting CBG or random $\mathrm{CBG}$ and underwent confirmatory testing were included in the study. Those with abnormal screening results for blood pressure and/or FPG, pregnant women and those who had self-reported previously diagnosed diabetes were excluded from this study.

\section{Data collection}

At the mass screening participants underwent measurements of weight and height and completed a structured questionnaire to collect data for the riskscore questionnaire. CBG screening for undiagnosed $\mathrm{DM}$ was done with a portable glucometer. Participants attended on another day for confirmatory testing for DM and pre-diabetes by fasting venous glucose blood levels after $\geq 8$ hours fast.

The high-risk score questionnaire used in this study was the diabetes risk test recommended by the ADA [15] and studied by Rolka et al. [16]. The questionnaire provides a high-risk score based on age, body mass index (BMI), sedentary lifestyle, family history of DM and ever having delivered a macrosomic baby ( $>4 \mathrm{~kg}$ ). The maximum score was 22 and the cut-off score for a positive screening result was $\geq 10$ points.

Capillary blood samples were taken and whole blood glucose concentration was measured using a uniform portable glucometer with the Medisafe Reader (Terumo Co.). During the field study, instruments were calibrated every morning. Supervision of the technicians carrying out the blood tests was ensured. Quality control supervised teams were distributed in every sector to assure the quality of performance and accuracy of the devices. Screening was considered positive if fasting CBG was $\geq 100 \mathrm{mg} /$ $\mathrm{dL}$ or if random CBG was $\geq 140 \mathrm{mg} / \mathrm{dL}$ for those with undiagnosed diabetes.

Venous blood specimens were collected and FPG concentrations were determined using glucose oxidase methodology in the central laboratory of the Dammam area or in other government and private hospitals. Type $2 \mathrm{DM}$ was diagnosed when FPG level was $\geq 126$ $\mathrm{mg} / \mathrm{dL}$ and pre-diabetes when FPG was $100-125 \mathrm{mg} / \mathrm{dL}$. Normal FPG was $<100 \mathrm{mg} / \mathrm{dL}$.

Laboratory personnel were blinded to the results of the screening test. Independent health team collected the questionnaires and the results of the screening tests, collated them with confirmatory FBS tests and delivered them to the main primary health directorate centre for data collection and entry.

\section{Analysis}

Different cut-off points of random CBG and fasting $\mathrm{CBG}$ and the risk-score questionnaire were evaluated separately 
against the diagnostic standard for diabetes (FPG $\geq 126 \mathrm{mg} / \mathrm{dL}$ ). Sensitivity, specificity, positive and negative predictive values, likelihood ratio of positive and negative tests, and 95\% confidence interval (CI) for all those were calculated using standard methods [17]. To select the optimal cut-off point for a positive test, a receiver operating characteristics (ROC) curve was constructed by plotting sensitivity (true positive rate) against the false positive rate (1-specificity). The high-risk score questionnaire and fasting and random CBG were evaluated with respect to the area under the curve (AUC) in the ROC.

All analyses were performed using SPSS for Windows, version 16.

\section{Results}

A total of 15082 individuals aged 30+ years were included in the study. DM was confirmed by FPG $\geq 126 \mathrm{mg} / \mathrm{dL}$ in $3052(20.3 \%)$ and pre-diabetes in 5108 (33.9\%) (Table 1). The characteristics of the study group of undiagnosed cases of DM according to socioeconomic status are shown in Table 2. The mean age was 46.5 (SD 11.6) years, 55.6\% were women and $47.9 \%$ had a first-degree relative with diabetes.

A total of 9919 people (65.8\%) had positive scores on the high-risk questionnaire (at the cut-off score of $\geq 10$ ) (Table 1). The sensitivity of the test at this cut-off was $71 \%$, while the specificity was 39\% (Table 3). However, combining the risk score for the fasting CBG and random CBG increased the sensitivity to $83 \%$ and $75 \%$ and specificity to $86 \%$ and $77 \%$ respectively. Figure 1 shows the ROC curve for the high-risk questionnaire; the AUC was 0.55 (95\% CI: 0.54-0.56).

In the biochemical screening tests, $10761(71.3 \%)$ participants were positive for either fasting CBG (at a cut-off of $100 \mathrm{mg} / \mathrm{dL}$ ) or random CBG (at a cut-off of $140 \mathrm{mg} / \mathrm{dL}$ ). Fasting CBG

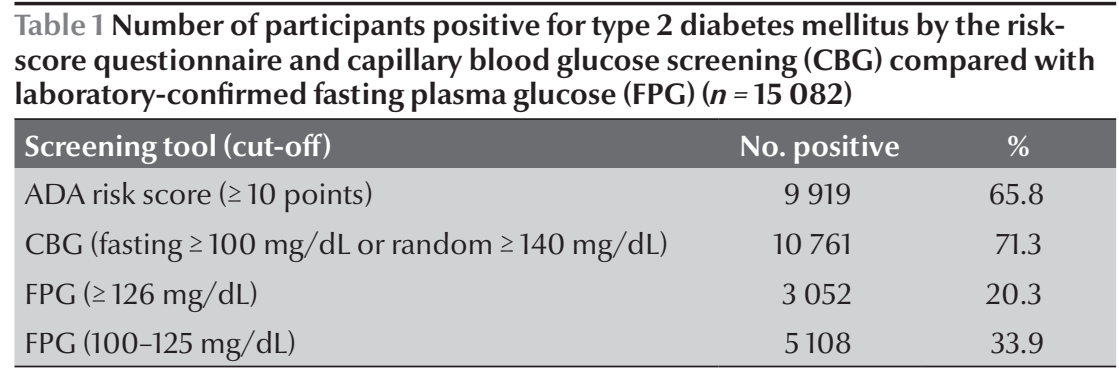

ADA $=$ American Diabetes Association .

was done for 4961 (32.9\%) participants, while random CBG was determined for 10121 (67.1\%). In Table 4 the diagnostic sensitivity, specificity and positive and negative predictive values of a positive test for both fasting and random CBS were compared with the FPG test at various cut-off points. Fasting CBG at $100 \mathrm{mg} / \mathrm{dL}$ had a sensitivity of $97 \%$ and specificity of $29 \%$. When the cut-off point was increased to 140 $\mathrm{mg} / \mathrm{dL}$ sensitivity dropped to $57 \%$ and specificity increased to $96 \%$. Random CBG at $140 \mathrm{mg} / \mathrm{dL}$ had a sensitivity of $91 \%$ and specificity of $48 \%$. When the cut-off point was increased to 200 $\mathrm{mg} / \mathrm{dL}$ sensitivity dropped to $53 \%$ and specificity increased to $95 \%$.

The optimal cut-off point (highest sensitivity with comparable high specificity) for fasting CBG was 120 $\mathrm{mg} / \mathrm{dL}$ (Table 4). Sensitivity was $81 \%$, specificity $86 \%$, positive predictive value $76 \%$ and negative predictive value $90 \%$. The likelihood ratio of a positive test was 5.88 and the likelihood ratio of a negative test was 0.22 .

For the random $\mathrm{CBG}$, the optimal cut-off point was $160 \mathrm{mg} / \mathrm{dL}$ (Table 4). Sensitivity was $76 \%$, specificity $77 \%$, positive predictive value $58 \%$, negative predictive value $89 \%$. The likelihood of a positive test was 3.35 and likelihood ratio of a negative test was 0.31 .

Figure 2 shows the ROC curve of the performance of fasting and random CBG. The AUC for random CBG (0.87) was lower than that for fasting CBG (0.82). If only those with positive high-risk scores were included, the AUC for fasting CBG increased to 0.87 and for random CBG dropped to 0.82 (Figure 3).

Table 5 shows the optimum cut-off point for both types of CBG screening tests according to sex. The optimum cut-off for random CBG screening was $165.5 \mathrm{mg} / \mathrm{dL}$ in men, with both a sensitivity and specificity of $77 \%$, and the cut-off for optimum random CBG in women was $159.5 \mathrm{mg} / \mathrm{dL}$, with lower sensitivity and specificity. The sensitivity and specificity for fasting CBG screening were higher in both men and women at cut-offs of $119.5 \mathrm{mg} / \mathrm{dL}$ and $121.5 \mathrm{mg} / \mathrm{dL}$ respectively.

\section{Discussion}

There is an increasing interest in using non-invasive tools such as risk-score questionnaires to detect high-risk groups suitable for screening. Finding a good high-risk score to detect undiagnosed $\mathrm{DM}$, which at the same time is simple enough not jeopardize compliance is difficult. This may be due to the overlap in the characteristics of DM types 1 and 2 [18] so that individuals do not always fit the typical pattern of type 2 DM [9]. Several multivariate equation models have been constructed to predict undiagnosed $\mathrm{DM}$, with variable rates of validity [6-10]. Spijkerman et al. found a different response to screening tools - the Cambridge risk score versus FPG and glycosylated haemoglobin $\left(\mathrm{HbA}_{1 \mathrm{c}}\right)$-among Caribbean and South Asian people living in the UK than the Caucasian population and recommended assessing the performance 


\begin{tabular}{|c|c|c|c|c|c|c|}
\hline \multirow[t]{3}{*}{ Variable } & \multirow{2}{*}{\multicolumn{2}{|c|}{$\begin{array}{c}\text { All } \\
(n=15082)\end{array}$}} & \multicolumn{4}{|c|}{ FPG results } \\
\hline & & & \multicolumn{2}{|c|}{ Type $2 \mathrm{DM}^{\mathrm{b}}(n=3052)$} & \multicolumn{2}{|c|}{ Pre-diabetes ${ }^{c}(n=5108)$} \\
\hline & No. & $\%$ & No. & $\%$ & No. & $\%$ \\
\hline \multicolumn{7}{|l|}{ Age (years) } \\
\hline $30-40$ & 4603 & 30.5 & 725 & 23.8 & 1368 & 26.8 \\
\hline $41-50$ & 5345 & 35.5 & 1104 & 36.2 & 1832 & 35.9 \\
\hline $51-60$ & 2869 & 19.0 & 650 & 21.3 & 1093 & 21.4 \\
\hline$>60$ & 2254 & 15.0 & 570 & 18.7 & 813 & 15.9 \\
\hline \multicolumn{7}{|l|}{ Sex } \\
\hline Male & 6673 & 44.4 & 1472 & 48.2 & 2121 & 41.5 \\
\hline Female & 8372 & 55.6 & 1580 & 51.8 & 2987 & 58.5 \\
\hline \multicolumn{7}{|l|}{ History } \\
\hline Family history of DM & 7220 & 47.9 & 1587 & 52.1 & 2438 & 47.8 \\
\hline Family history of hypertension & 6606 & 43.9 & 1277 & 42.0 & 2239 & 47.8 \\
\hline $\begin{array}{l}\text { History of gestational DM } \\
\text { (women) }\end{array}$ & 1445 & 17.2 & 397 & 24.8 & 497 & 16.7 \\
\hline \multicolumn{7}{|l|}{ Marital status } \\
\hline Single & 429 & 2.9 & 77 & 2.5 & 126 & 2.5 \\
\hline Married & 13142 & 87.9 & 2652 & 87.8 & 4430 & 87.4 \\
\hline Widowed & 1142 & 7.6 & 243 & 8.0 & 425 & 8.4 \\
\hline Divorced & 230 & 1.5 & 48 & 1.6 & 86 & 1.7 \\
\hline \multicolumn{7}{|l|}{ Occupation } \\
\hline Self-employed & 1180 & 8.0 & 286 & 9.6 & 358 & 7.1 \\
\hline Housewife & 7103 & 48.0 & 1375 & 46.0 & 2578 & 51.5 \\
\hline Military & 1434 & 9.7 & 301 & 10.1 & 459 & 9.2 \\
\hline Professional & 994 & 6.7 & 169 & 5.7 & 300 & 6.0 \\
\hline Technical & 464 & 3.1 & 82 & 2.7 & 143 & 2.9 \\
\hline Non-technical & 611 & 4.1 & 124 & 4.2 & 201 & 4.0 \\
\hline Administrative employee & 1709 & 11.6 & 332 & 11.1 & 522 & 10.4 \\
\hline Unemployed & 1288 & 8.7 & 318 & 10.6 & 448 & 8.9 \\
\hline \multicolumn{7}{|l|}{ Education } \\
\hline Illiterate & 5824 & 39.3 & 1281 & 42.8 & 2162 & 43.1 \\
\hline Read \& write & 1288 & 8.7 & 288 & 9.6 & 439 & 8.7 \\
\hline Primary & 2449 & 16.5 & 485 & 16.2 & 793 & 15.8 \\
\hline Intermediate & 1755 & 11.9 & 359 & 12.0 & 577 & 11.5 \\
\hline Secondary & 2029 & 13.7 & 352 & 11.8 & 604 & 12.0 \\
\hline University & 1373 & 9.3 & 206 & 6.9 & 425 & 8.5 \\
\hline Higher degree & 83 & 0.6 & 19 & 0.6 & 22 & 0.4 \\
\hline \multicolumn{7}{|l|}{ Income (Saudi riyals) } \\
\hline$<2000$ & 4051 & 30.0 & 873 & 32.2 & 1447 & 31.6 \\
\hline $2000-<5000$ & 4415 & 32.7 & 889 & 32.7 & 1465 & 32.0 \\
\hline $5000-<7000$ & 2365 & 17.5 & 461 & 17.0 & 835 & 18.2 \\
\hline$>7000$ & 2651 & 19.7 & 492 & 18.1 & 837 & 18.3 \\
\hline
\end{tabular}

${ }^{a}$ Total varies due to missing data.

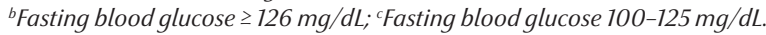



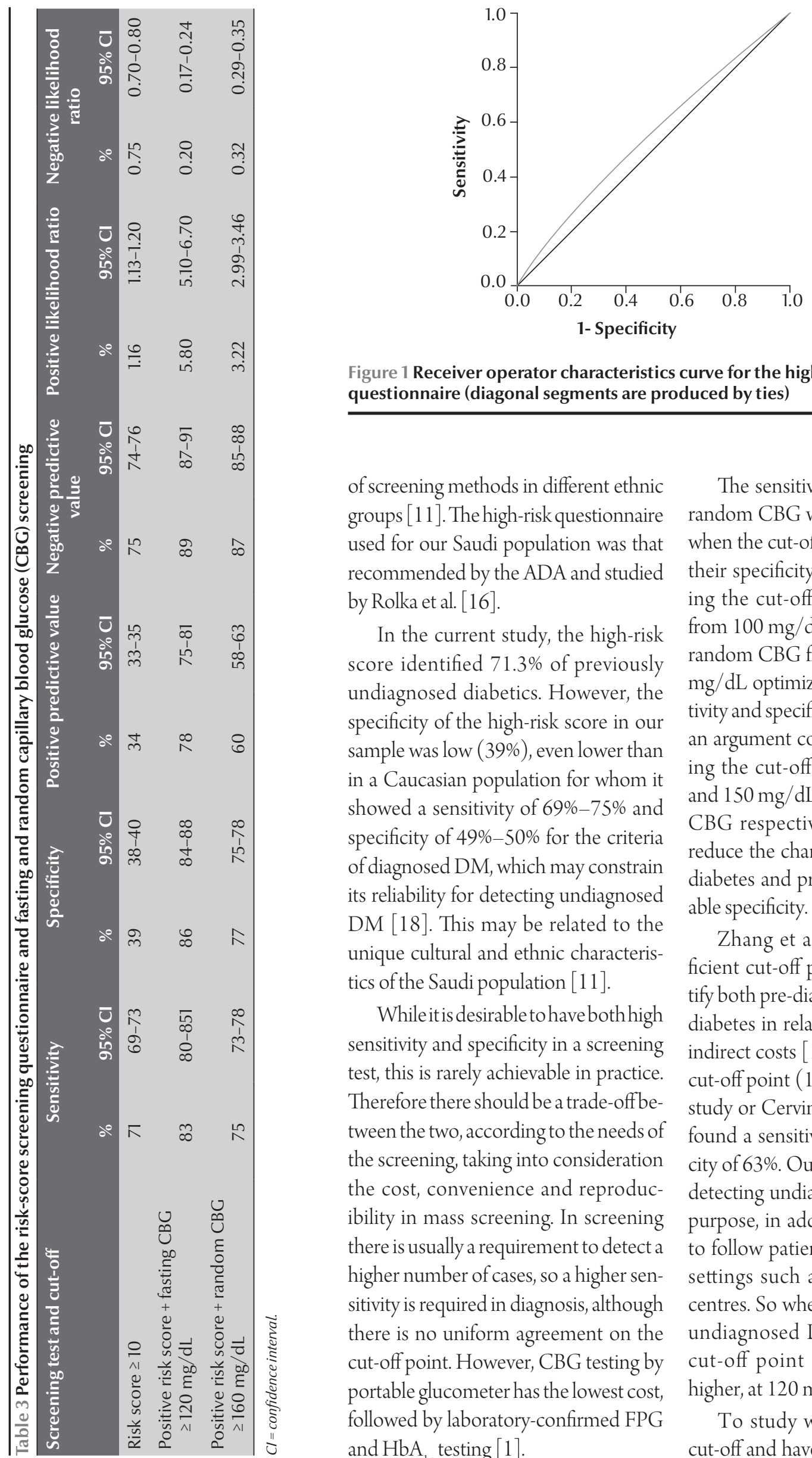

Figure 1 Receiver operator characteristics curve for the high-risk screening questionnaire (diagonal segments are produced by ties)

of screening methods in different ethnic groups [11]. The high-risk questionnaire used for our Saudi population was that recommended by the ADA and studied by Rolka et al. [16].

In the current study, the high-risk score identified $71.3 \%$ of previously undiagnosed diabetics. However, the specificity of the high-risk score in our sample was low (39\%), even lower than in a Caucasian population for whom it showed a sensitivity of $69 \%-75 \%$ and specificity of $49 \%-50 \%$ for the criteria of diagnosed DM, which may constrain its reliability for detecting undiagnosed DM [18]. This may be related to the unique cultural and ethnic characteristics of the Saudi population [11].

While it is desirable to have both high sensitivity and specificity in a screening test, this is rarely achievable in practice. Therefore there should be a trade-off between the two, according to the needs of the screening, taking into consideration the cost, convenience and reproducibility in mass screening. In screening there is usually a requirement to detect a higher number of cases, so a higher sensitivity is required in diagnosis, although there is no uniform agreement on the cut-off point. However, CBG testing by portable glucometer has the lowest cost, followed by laboratory-confirmed FPG and $\mathrm{HbA}_{1 \mathrm{c}}$ testing [1].
The sensitivity of fasting CBG and random CBG were higher in our study when the cut-off point was lowered but their specificity was very low. Increasing the cut-off point of fasting $\mathrm{CBG}$ from $100 \mathrm{mg} / \mathrm{dL}$ to $120 \mathrm{mg} / \mathrm{dL}$ and of random CBG from $140 \mathrm{mg} / \mathrm{dL}$ to 160 $\mathrm{mg} / \mathrm{dL}$ optimized the balance of sensitivity and specificity. On the other hand, an argument could be made for lowering the cut-off points to $110 \mathrm{mg} / \mathrm{dL}$ and $150 \mathrm{mg} / \mathrm{dL}$ for fasting and random CBG respectively and consequently reduce the chances of missing cases of diabetes and pre-diabetes with reasonable specificity.

Zhang et al. studied the most efficient cut-off point for CBG to identify both pre-diabetes and undiagnosed diabetes in relation to both direct and indirect costs [19]. They chose a lower cut-off point $(100 \mathrm{mg} / \mathrm{dL})$ than in our study or Cervin et al.'s study [18], and found a sensitivity of $83 \%$ and specificity of $63 \%$. Our study focused only on detecting undiagnosed DM. The main purpose, in addition to detection, was to follow patients through health care settings such as primary health care centres. So when focused on detecting undiagnosed DM the most efficient cut-off point for fasting CBG was higher, at $120 \mathrm{mg} / \mathrm{dL}$.

To study whether to use a lower cut-off and have a lower specificity or a 


\begin{tabular}{|c|c|c|c|c|c|c|c|c|c|c|c|c|}
\hline \multirow[t]{2}{*}{$\begin{array}{l}\text { Cut-off } \\
(\mathrm{mg} / \mathrm{dL})\end{array}$} & \multicolumn{2}{|c|}{ Sensitivity } & \multicolumn{2}{|c|}{ Specificity } & \multicolumn{2}{|c|}{$\begin{array}{l}\text { Positive } \\
\text { predictive value }\end{array}$} & \multicolumn{2}{|c|}{$\begin{array}{c}\text { Negative } \\
\text { predictive value }\end{array}$} & \multicolumn{2}{|c|}{$\begin{array}{c}\text { Positive } \\
\text { likelihood ratio }\end{array}$} & \multicolumn{2}{|c|}{$\begin{array}{c}\text { Negative } \\
\text { likelihood ratio }\end{array}$} \\
\hline & $\%$ & $95 \% \mathrm{Cl}$ & $\%$ & $95 \% \mathrm{Cl}$ & $\%$ & $95 \% \mathrm{Cl}$ & $\%$ & $95 \% \mathrm{Cl}$ & $\%$ & $95 \% \mathrm{Cl}$ & $\%$ & $95 \% \mathrm{Cl}$ \\
\hline & \multicolumn{12}{|c|}{ Fasting } \\
\hline 100 & 97 & $96-98$ & 29 & $27-31$ & 42 & $40-44$ & 95 & $93-97$ & 1.37 & $1.33-1.41$ & 0.09 & $0.07-0.13$ \\
\hline 110 & 91 & 89-93 & 67 & $65-69$ & 59 & $56-61$ & 93 & 92-95 & 2.72 & $2.55-2.90$ & 0.14 & $0.11-0.16$ \\
\hline 120 & 81 & $79-83$ & 86 & $85-88$ & 76 & $73-78$ & 90 & $88-91$ & 5.88 & $5.25-6.58$ & 0.22 & $0.19-0.25$ \\
\hline 130 & 70 & $67-73$ & 93 & $92-94$ & 85 & $82-87$ & 86 & $84-87$ & 10.55 & 8.92-12.48 & 0.32 & $0.29-0.35$ \\
\hline \multirow[t]{2}{*}{140} & 57 & $54-60$ & 96 & $95-97$ & 88 & $85-90$ & 81 & 79-83 & 13.98 & $11.25-17.36$ & 0.45 & $0.42-0.48$ \\
\hline & \multicolumn{12}{|c|}{ Random } \\
\hline 140 & 91 & $90-92$ & 48 & $47-50$ & 42 & $40-43$ & 93 & $92-94$ & 1.76 & $1.70-1.81$ & 0.18 & $0.16-0.21$ \\
\hline 150 & 84 & 83-86 & 65 & $64-66$ & 50 & $48-51$ & 91 & $90-92$ & 2.41 & $2.30-2.51$ & 0.24 & $0.22-0.27$ \\
\hline 160 & 76 & $74-78$ & 77 & $76-79$ & 58 & $56-60$ & 89 & $88-90$ & 3.35 & $3.16-3.55$ & 0.31 & $0.29-0.34$ \\
\hline 170 & 69 & 70-71 & 86 & $85-87$ & 66 & 64-68 & 87 & $86-88$ & 4.77 & $4.43-5.14$ & 0.36 & $0.34-0.39$ \\
\hline 180 & 63 & $61-65$ & 90 & 89-91 & 72 & $70-74$ & 86 & 85-87 & 6.35 & $5.79-6.95$ & 0.41 & $0.39-0.44$ \\
\hline 190 & 57 & $55-60$ & 93 & $92-94$ & 77 & $75-79$ & 84 & 83-85 & 8.29 & $7.43-9.26$ & 0.46 & $0.43-0.48$ \\
\hline 200 & 53 & $51-55$ & 95 & $94-96$ & 81 & $79-84$ & 83 & $82-84$ & 10.75 & $9.43-12.24$ & 0.50 & $0.47-0.52$ \\
\hline
\end{tabular}

$\mathrm{Cl}=$ confidence interval.

higher cut-off and have lower sensitivity, we used ROC curves to determine whether to use fasting or random $\mathrm{CBG}$. The AUC for fasting CBG was higher (0.87) than for random CBG (0.82). Rolka et al. reported similar findings: CBG screening in participants who had not eaten for $\geq 8$ hours had a higher sensitivity and specificity in both sexes compared with random CBG [16].
It was clear from our data that the high-risk questionnaire performed poorly when carried out alone, with a sensitivity of $71 \%$ and specificity of $39 \%$. Even when a positive high-risk score was used in conjunction with portable CBG screening, sensitivity increased from $71 \%$ to $83 \%$. However, other predictors did not change or were negatively affected, and this may be due to the high percentage of the study population who were obese or overweight. Threequarters of the population of Eastern province of Saudi Arabia are obese or overweight [20]. Besides, the age of the study participants was $\geq 30$ years. So, based on those factors, the ability to discriminate between those who had and those who did not have the disease was low.

Ourstudy had a number of strengths including the large size of the population (a)

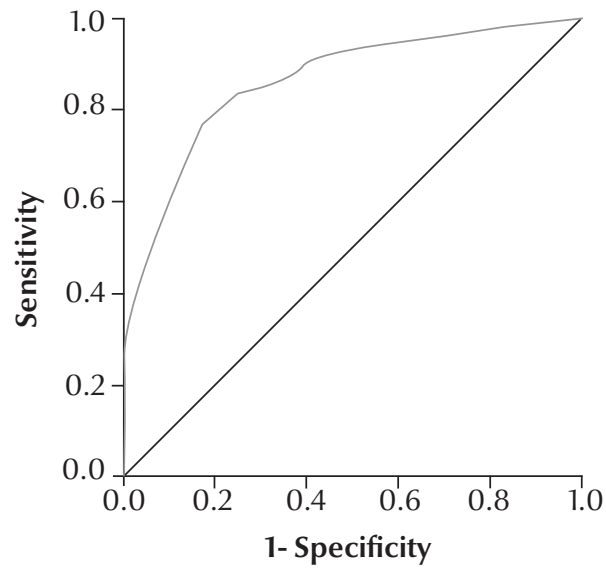

(b)

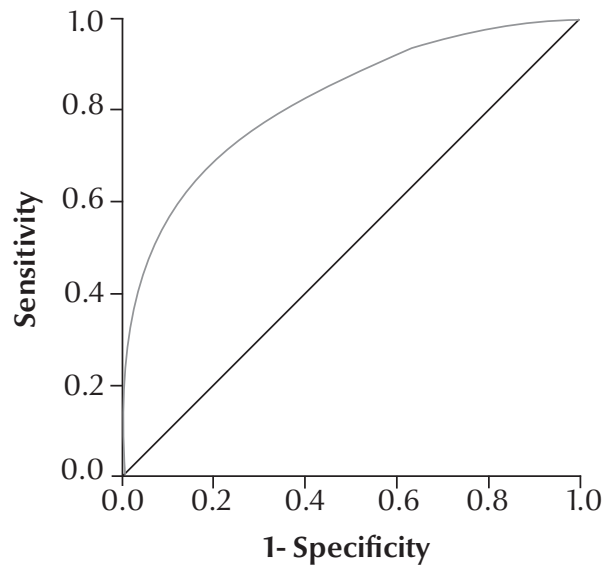

Figure 2 Receiver operator characteristics curve for (a) fasting capillary blood glucose screening test and (b) random capillary blood glucose screening test (diagonal segments are produced by ties) 
(a)

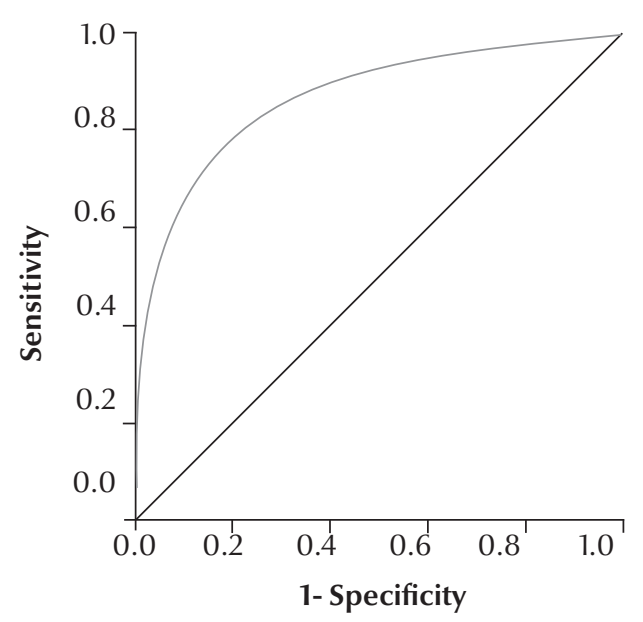

(b)

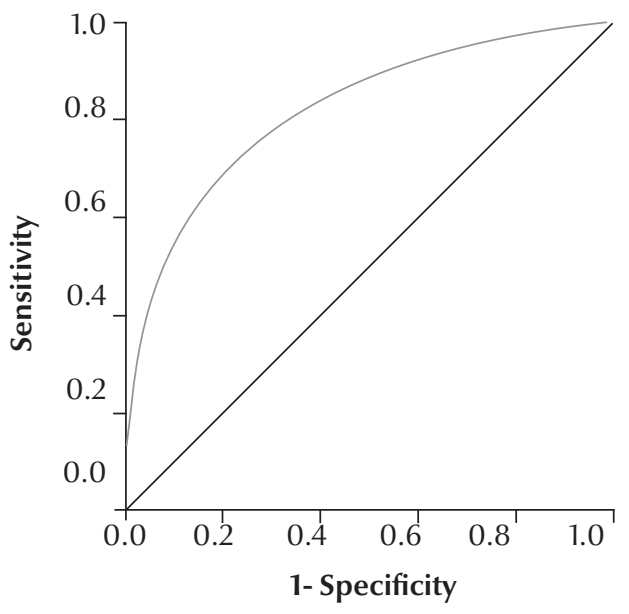

Figure 3 Receiver operator characteristics curve of (a) fasting capillary blood glucose screening test and (b) random capillary blood glucose screening test if administered after positive high-risk score (Diagonal segments are produced by ties)

\begin{tabular}{|c|c|c|c|c|c|}
\hline Test/Sex & No. tested & $\operatorname{AUC}(95 \% \mathrm{Cl})$ & Cut-off (mg/dL) & Sensitivity (\%) & Specificity (\%) \\
\hline \multicolumn{6}{|c|}{ Random CBG } \\
\hline Male & 5104 & $0.85(0.84-0.87)$ & 165.5 & 77 & 77 \\
\hline Female & 4991 & $0.79(0.77-0.80)$ & 159.5 & 70 & 71 \\
\hline \multicolumn{6}{|c|}{ Fasting CBG } \\
\hline Male & 1475 & $0.89(0.87-0.91)$ & 119.5 & 82 & 82 \\
\hline Female & 3380 & $0.85(0.83-0.87)$ & 121.5 & 78 & 79 \\
\hline
\end{tabular}

$A \cup C=$ area under the curve $C I=$ confidence interval.

enrolled in the campaign, the diversity of subgroups, and the study design, in which the laboratory personnel carrying out the confirmatory FPG testing were not aware of the previous results of CBG screening. FPG was selected for this study as the diagnostic standard because it is a convenient test to ensure compliance of the participants, especially with large number of participants enrolled in this campaign.

\section{Conclusions}

The risk-score questionnaire did not perform well versus fasting and random CBG. The optimal cut-off points for fasting and random CBG were $120 \mathrm{mg} /$ $\mathrm{dL}$ and $160 \mathrm{mg} / \mathrm{dL}$ respectively. Fasting CBG had higher sensitivity, specificity and discriminating ability than random CBG for detection of diabetes and pre-diabetes in this population.

\section{Acknowledgements}

We thank all who participated in the campaign for their enthusiasm to fulfil its objectives. Our thanks also go to the Ministry of Health, Al-Dawaa Pharmacy and Al-Qusaibi Company for funding this study, and to Dr Mohamed Anwar Al-Yousef, Dr Ali Al-Atabani and Dr Jamal Al-Hamed for their active contribution in the campaign.

\section{References}

1. American Diabetes Association. Standards of medical care in diabetes-2008. Diabetes Care, 2008, 31(Suppl. 1):S12-54.

2. U.S. Preventive Services Task Force. Guide to clinical preventive services: report of the U.S. Preventive Services Task Force. Baltimore, Maryland, Williams \& Wilkins, 2003.

3. The Diabetes Control and Complications Trial Research Group. The effect of intensive treatment of diabetes on the development and progression of long-term complications in insulin-dependent diabetes mellitus. New England Journal of Medicine, 1993, 329:977-986.

4. UK Prospective Diabetes Study 6: complications in newly diagnosed type 2 diabetic patients and their association with different clinical and biochemical risk factors. Diabetes Research (Edinburgh, Lothian), 1990, 13:1-11. 
5. Herman WH et al. A new and simple questionnaire to identify people at increased risk for undiagnosed diabetes. Diabetes Care, 1995, 18:382-387.

6. Griffin SJ et al. Diabetes risk score: towards earlier detection of type 2 diabetes in general practice. Diabetes/Metabolism Research and Reviews, 2000, 16:164-171.

7. Baan CA et al. Performance of a predictive model to identify undiagnosed diabetes in a health care setting. Diabetes Care, 1999, 22:213-219.

8. Tabaei BP, Herman WH. A multivariate logistic regression equation to screen for diabetes: development and validation. Diabetes Care, 2002, 25:1999-2003.

9. Glümer $\mathrm{C}$ et al. A Danish diabetes risk score for targeted screening: the Inter99 study. Diabetes Care, 2004, 27:727-733.

10. Heikes KE et al. Diabetes risk calculator: a simple tool for detecting undiagnosed diabetes and pre-diabetes. Diabetes Care, 2008, 31:1040-1045

11. Spijkerman AMW et al. The performance of a risk score as a screening test for undiagnosed hyperglycemia in ethnic minority groups: data from the 1999 health survey for England. Diabetes Care, 2004, 27:116-122.

12. Al-Nozha MM et al. Diabetes mellitus in Saudi Arabia. Saudi Medical Journal, 2004, 25:1603-1610.

13. Al-Ghamdi et al. A community-based screening campaign for the detection of diabetes mellitus and hypertension in the eastern province, Saudi Arabia: methods and participation rate. Journal of Family and Community Medicine, 2007, 14(3):91-97.

14. Al-Baghli A et al. Control of diabetes mellitus in the Eastern province of Saudi Arabia: results of screening campaign. Eastern Mediterranean Health Journal, 2010, 16(6):621-629.

15. Diabetes risk test. American Diabetes Association [website] (http://www.diabetes.org/diabetes-basics/prevention/diabetes-risk-test/, accessed 29 September 2010).

16. Rolka DB et al. Performance of recommended screening tests for undiagnosed diabetes and dysglycemia. Diabetes Care, 2001, 24:1899-1903.

17. Stats calculator. Center for Evidence Based Medicine [website] (http://cebm.utoronto.ca/practise/ca/statscal/, accessed 31 August 2010).

18. Cervin $\mathrm{C}$ et al. Genetic similarities between latent autoimmune diabetes in adults, type 1 diabetes, and type 2 diabetes. Diabetes, 2008, 57:1433-1437.

19. Zhang $P$ et al. Efficient cutoff points for three screening tests for detecting undiagnosed diabetes and pre-diabetes: an economic analysis. Diabetes Care, 2005, 28:1321-1325.

20. Al-Baghli AN et al. Overweight and obesity in the Eastern province of Saudi Arabia. Saudi Medical Journal, 2008, 29:13191325.

\section{Diabetes in the Eastern Mediterranean Region}

Diabetes mellitus is highly prevalent among both sexes in Member States of the WHO Eastern Mediterranean Region, ranging from 3.5\% to 30.0\% and it is highest among member countries of the Gulf Cooperation Council (GCC) at $11.5 \%$ to $30.0 \%$. Many countries in the Region are now reporting the onset of type 2 diabetes mellitus at an increasingly young age. This is due to increasingly sedentary lifestyles, higher life expectancy and obesity. High blood pressure and cardiovascular diseases are also on the rise. In 2003, the 5 countries with the highest diabetes prevalence in the adult population were Nauru (30.2\%), United Arab Emirates (20.1\%), Qatar (16\%), Bahrain (14.9\%), and Kuwait (12.8\%) (1). By 2025, the number of people with diabetes is expected to be more than double in Africa, the Eastern Mediterranean and South-East Asia regions.

Further information on the Regional prevalence of this condition can be found on the noncommunicable diseases website at http://www.emro.who.int/ncd/diabetes.htm/ 